\title{
A utilização dos recursos energéticos no rio Itajaí-Açú (SC)
}

\section{The use of energy resources in Itajaí-Açú river}

\author{
Simoni Mendes de Paula ${ }^{1}$
}

Resumo: Este trabalho tem como objetivo analisar os projetos para a produção de energia elétrica no rio Itajaí-Açú, em Santa Catarina. No último quartel do século XIX, indústrias como a Hering e a Karsten iniciaram sua produção utilizando-se da energia hidráulica produzida na região do Testo Salto. Nas décadas seguintes, empresas como a Empresa Eletricidade do Salto e a Empresa Força e Luz ratificaram o potencial hidrelétrico do vale do Itajaí com a construção de usinas hidrelétricas. Transformando o rio, até então conhecido pelas enchentes, em um aliado para o desenvolvimento da cidade.

Palavras-Chave: Itajaí-Açú, Recursos energéticos, Usinas Hidrelétricas.
Abstract: This study aims to analyze the projects for the production of electricity in the River Itajaí-Açú, in Santa Catarina. In the last quarter of the nineteenth century, industries such as Hering and Karsten started production using hydroelectric power from the Testo Salto region. In the following decades, companies like Empresa Eletricidade Salto and Empresa Força e Luz ratified the hydroelectric potential of the Itajaí valley with the construction of hydroelectric plants. Transforming the river, then known by the floods, an ally to the development of the city.

Keywords: Itajaí-Açú, energy resources, hydroelectric plants.

${ }^{1}$ Mestre em História Cultural pela Universidade Federal de Santa Catarina. Atualmente, doutoranda do Programa de Pós-Graduação em História na Universidade Federal de Santa Catarina. E-mail: Simoni.mendes@yahoo.com.br. Bolsista CAPES.

Fronteiras: Revista Catarinense de História [on-line], Florianópolis, n.23, p.164-179, 2014 


\section{A importância da energia hidrelétrica na industrialização do Vale do Itajaí}

A utilização dos recursos hídricos tem acompanhado as sociedades desde o princípio. O aproveitamento das águas recai, na maioria das vezes, sobre as águas doces, visto que a dessalinização das águas exige um elevado custo financeiro e conhecimento técnico, que acaba prejudicando a realização do processo em grande escala. Esses recursos extraídos das águas são diversos e imprescindíveis para manutenção da sociedade, seja em sua relação com a higiene, alimentação, navegação, irrigação, energia elétrica, entre outros ${ }^{2}$. Em virtude das formas de utilização dos recursos hídricos acima mencionados, os rios são elementos de extrema importância no desenvolvimento das sociedades, bem como no equilíbrio dos sistemas ambientais em que estão inseridos.

Onde há um rio, há a utilização dos recursos por ele oferecidos, há, em alguns casos, os desastres ambientais surgidos em função da má utilização desses recursos e há, sobretudo, uma sociedade que apesar de nem sempre cuidar como deveria, encontra-se intimamente dependente destes recursos oferecidos pelo rio. A região do Vale do Itajaí, que tem o Rio Itajaí-Açú como seu principal rio, assim como muitos outros vales do mundo, apresenta uma história socioeconômica ligada às ações e recursos explorados do rio. Desta forma, este artigo tem o objetivo de analisar os projetos de produção de energia elétrica através da utilização das águas do rio Itajaí-Açú, demonstrando assim, que a relação da sociedade com o rio em questão não se resume apenas as enchentes, tão frequentes na sua história.

Uma cidade reconhecidamente industrial, como Blumenau (principal cidade do Vale do Itajaí), não encontrou nas águas do Itajaí-Açú apenas enchentes e desastres, mas também a força necessária para gerar energia para alimentar suas recém-criadas indústrias têxteis. Essa nova forma de aproveitamento dos recursos hídricos se apresentou como uma nova relação firmada entre a cidade e o rio. Relação esta, baseada na domesticação, talvez parcial, da força das águas.

\subsection{O processo de industrialização do Vale do Itajaí}

2 VARGAS, Marcelo Coutinho. O gerenciamento integrado dos recursos hídricos como problema socioambiental. Ambiente \& Sociedade, São Paulo, n. 5, p. 109, 1999. 
Para compreender a importância econômica que a utilização dos recursos hídricos, enquanto fontes de energia elétrica, tiveram para o Vale do Itajaí, faz-se necessário entender um pouco da formação e do funcionamento da sociedade industrial que começou a se constituir no fim do século XIX. Quando se estabeleceu às margens do rio Itajaí-Açú, a colônia Blumenau buscou se firmar, economicamente, como uma sociedade rural, por meio da pequena propriedade e oferecendo acesso a terra para todos os colonos que a desejassem. O momento político por qual passava a Europa, no entanto, acabou estimulando a vinda de industriais e artesãos, pessoas que, apesar de não estarem ligados ao trabalho rural, pretendiam crescer na América.

Enquanto as três primeiras décadas após a implantação da colônia Blumenau foram marcadas pela intensa produção rural, apenas com alguns comércios espalhados pelo centro da colônia, as décadas subsequentes marcaram o início de um novo ciclo econômico. A partir de 1880, as indústrias têxteis entram em cena, com a fundação de embriões do que viriam a ser alguns grandes expoentes da economia catarinense até hoje, como a famosa Cia. Hering. Segundo o cientista social Marcos Antônio Mattedi $^{3}$, o período entre 1880 e 1914 corresponde a primeira fase da industrialização do Vale do Itajaí. Fase esta encerrada com o florescimento da nova relação sociedade/rio, com a construção da primeira grande usina hidrelétrica da região.

A Cia. Hering foi a pioneira do vale, fundada pelos irmãos Hermann e Bruno Hering, ambos nascidos na Alemanha. Hermann foi o primeiro a emigrar, deixou em sua terra natal esposa e filhos, com a promessa de se estabelecer na nova terra e só então chamá-los para Blumenau. De família de tecelões oriundos da Saxônia, Hermann nunca se dedicou ao trabalho na terra. Antes da fundação da indústria têxtil, o imigrante se dedicou à manufatura de charuto e ao comércio ${ }^{4}$. No ano de 1880 , com o auxílio do irmão Bruno e da família que já se encontrava no Brasil, entra em funcionamento a Cia. Hering.

\footnotetext{
${ }^{3}$ MATTEDI, Marcos Antônio. Subsídios para a Análise das Relações Sociedade-Natureza no Vale do Itajaí. In: THEIS, Ivo Marcos, et al. (Org.). Nosso Passado (In)comum: Contribuições para o debate sobre a história e a historiografia em Blumenau. Blumenau: Ed. da FURB: Ed Cultura em Movimento, 2000. p. 230.

${ }^{4}$ HERING, Maria Luiza Renaux. Colonização e Indústria no Vale do Itajaí: o modelo catarinense de desenvolvimento. Blumenau: editora da FURB, 1987. p. 87 - 88.
} 
Após a fundação da Hering, ocorreu a criação do Industrial Garcia e da fábrica de tecidos Roeder, Karsten \& Hadlich, ambas também localizadas em Blumenau. Além da fábrica de tecidos Carlos Renaux, esta sediada em Brusque. É importante destacar que esses industriais tinham contatos frequentes com sua terra natal, para a aquisição de material para suas fábricas, tecnologias e o próprio conhecimento adquirido em suas vivências em plena Revolução Industrial ( $2^{\circ}$ Revolução) antes de sua partida para o Brasil. Esse know-how, aliado ao financiamento conquistado com alguns bancos alemães, fez com que as indústrias do vale rapidamente prosperassem.

Com o desenvolvimento chegando à velha colônia, um problema latente em todo o Brasil industrial se fez presente: como produzir energia para abastecer uma indústria? Parecia claro que enquanto o Brasil não garantisse sua produção energética, o desenvolvimento e a modernização não seriam tarefas fáceis. No início do século XX, era objeto de discussão entre os principais interessados a necessidade de produzir eletricidade. Para o engenheiro J. Brant Carvalho, a "[...] engenharia permitiria harmonizar o regime das águas fluviais de forma a conciliar os interesses da agricultura com os da indústria - uma negação, na prática, da tese de que a vocação brasileira era essencialmente agrária" ${ }^{5}$.

Os primeiros anos das indústrias foram marcados pela produção de sua própria energia, por meio de rodas d'água, localizadas próximas às fábricas. Em virtude dessa necessidade de implantação das indústrias nas proximidades dos rios, percebe-se claramente, que assim como havia ocorrido no início da colônia ${ }^{6}$, o curso dos rios da bacia hidrográfica do Itajaí ditaram a construção do espaço urbano do vale. Além do curso do rio, outros fatores condicionaram o desenvolvimento da malha urbana, dentre as quais se destacam a propriedade do terreno e a presença de mão de obra em áreas rurais (principalmente na segunda fase do desenvolvimento industrial,

${ }^{5}$ CARVALHO apud MAGALHÃES, Gildo. Força e Luz: eletricidade e modernização na república velha. SãoPaulo: Editora da UNESP; FAPESP, 2000. p. 56.

${ }^{6}$ Os lotes dos primeiros colonos do Vale do Itajaí buscavam seguir o curso do rio. Isso se deve ao fato de que era preciso recorrer aos recursos hídricos, seja para irrigação das plantações ou para a navegação (o rio Itajaí-Açú era o único caminho que ligava a colônia ao litoral, não havia estradas). Para mais informações ler: SEYFERTH, Giralda. A colonização alemã no Vale do Itajaí Mirim: um estudo de desenvolvimento econômico. Porto Alegre: Movimento, 1974. 
quando o trabalho rural já não era mais uma opção para o sustento completo da família) ${ }^{7}$.

É possível observar que a industrialização agravou um problema constante de Blumenau, as enchentes. Essa ocupação de áreas próximas às margens intensificou o desmatamento, contribuindo para que os desastres se tornassem cada vez mais frequentes. Não é por menos que, ao longo de sua história, várias dessas indústrias tiveram que enfrentar as inundações, que as faziam perder grande parte do seu maquinário. A empresa da família Hering, por exemplo, enfrentou uma grande enchente no mês seguinte a sua fundação, em setembro de 1880, na qual foi inutilizado o único tear, peça responsável pelo sustento da família. Para se reerguer, foi necessário recorrer a um empréstimo junto ao Dr. Blumenau, então diretor geral da colônia, a fim de comprar nova remessa de fios, já que todos os recursos que a fábrica possuía haviam sido empregados na recuperação dos prejuízos causados pela enchente ${ }^{8}$.

Em 1893, a fábrica Hering migrou do centro da cidade para o bairro Bom Retiro, às margens do ribeirão Bom Retiro, para suprir a necessidade de força hidráulica e aumentar o número de teares para atender a demanda comercial. Da mesma forma, o colono Johann Karsten, pioneiro da fábrica de tecidos Roeder, Karsten \& Hadlich resolveu aproveitar a queda d'agua do Rio do Testo, local onde se dedicava às atividades rurais, para instalar uma tecelagem. O Mapa 1, de 1864, traz a distribuição dos lotes da então colônia seguindo o curso do rio Itajaí-Açú (ao centro do mapa) e seus afluentes, sendo possível observar o curso do rio do Testo, com destaque em azul e o ribeirão Bom Retiro, em vermelho. Em Brusque a organização foi a mesma, a fábrica de Carlos Renaux, que por algum tempo funcionou no centro da cidade, foi transferida para um terreno localizado na Rua dos Pomeranos. Nesse novo local, havia uma lagoa de onde se represava a água para acionar a turbina, que com a ajuda de um pequeno gerador de força elétrica, produzia energia para movimentar os teares 9 .

${ }^{7}$ MORETTI, Silvana Maria. Fábrica e espaço urbano: a influência da industrialização na formação dos bairros e no desenvolvimento da vida urbana em Blumenau. Florianópolis, 2006. 263 f. Dissertação (Mestrado) - Universidade Federal de Santa Catarina, Centro de Filosofia e Ciências Humanas, Programa de Pós-Graduação em Geografia, Florianópolis, 2006, p. 118.

${ }^{8}$ HERING, op. cit, p. 93.

${ }^{9}$ Ibidem, p. 128. 
Mapa 1: Mapa de distribuição dos lotes na colônia Blumenau (1864). Escala: 1: 167.461 (grifo da autora).

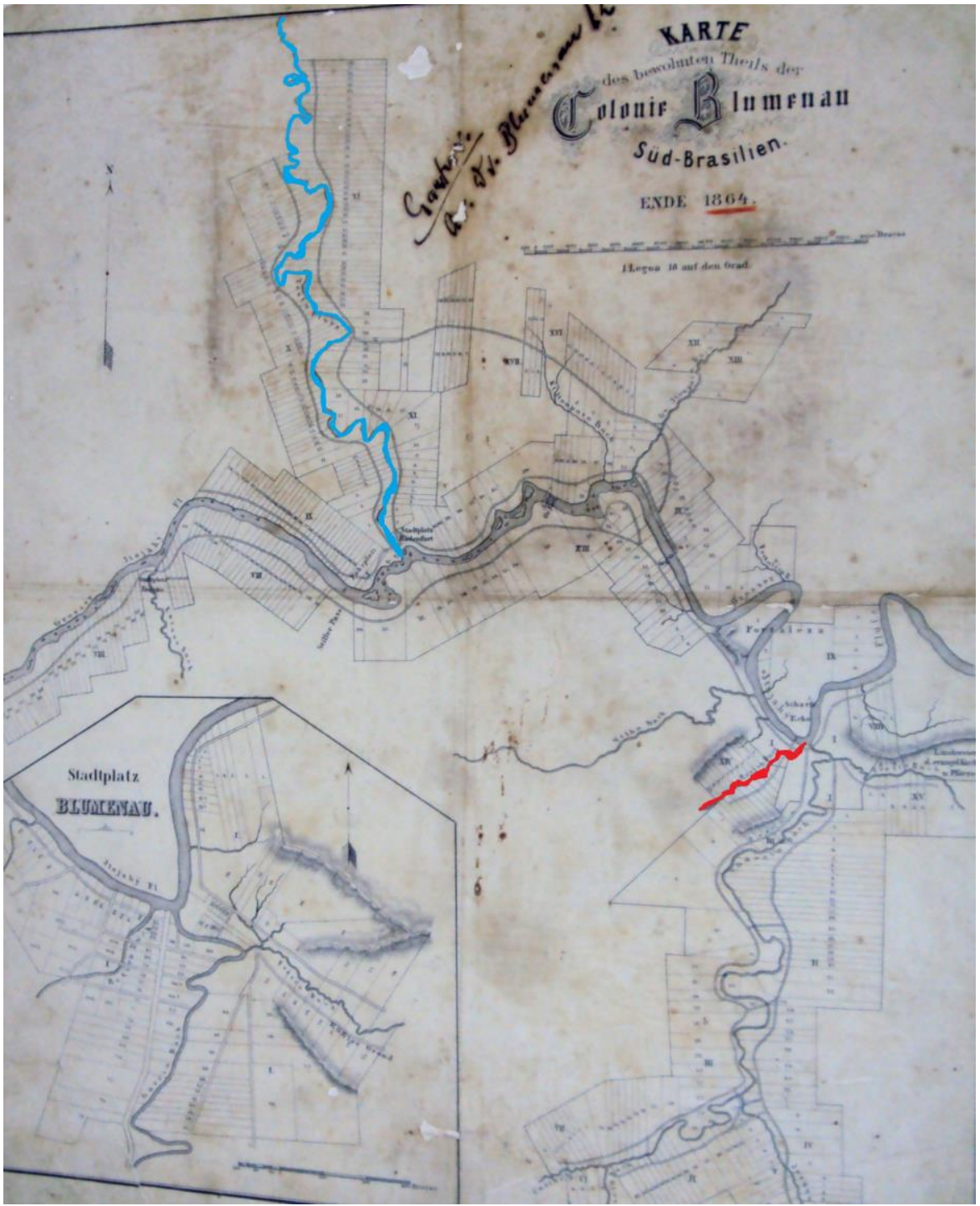

Fonte: Arquivo Histórico José Ferreira da Silva. 
Após as décadas de enchentes frequentes, ocasionadas em partes pela ocupação das margens dos rios, e em um momento em que a força hidráulica não precisava mais estar próxima, visto que a energia elétrica já era uma realidade para todos, o curso do rio continuou guiando a construção do espaço urbano. A partir da segunda metade do século XX percebe-se que há uma tendência de instalar as indústrias nos pontos mais altos. Isso com a intenção de fugir das enchentes, que muito maquinário destruiu ao longo das décadas ${ }^{10}$. Em fim, a ocupação física do Vale do Itajaí, sempre esteve e sempre estará condicionada pela relação ambivalente criada entre o rio e a sociedade. Em um momento se quer e se precisa estar perto, em outro se deseja estar longe.

\section{2 - A criação das usinas hidrelétricas no Vale do Itajaí}

As rodas d'água e geradores próprios foram utilizadas durante cerca de trinta anos. Com o passar do tempo e o aumento da produção, a energia fornecida tornou-se mísera diante da crescente indústria do vale, que começava a entrar no mercado de exportação, nacional e internacional, e necessitava de uma produção muito maior. Para isso, uma série de discussões e análises começou a ser feita para escolher o ponto da bacia ideal para a instalação daquela que seria a primeira grande usina hidrelétrica do Vale do Itajaí e de todo Estado.

Já em fins do século XIX, alguns orçamentos começaram a ser apresentados para a construção de uma usina hidrelétrica que deveria ser implantada na localidade do Salto Weissbach, em Blumenau, no curso do Rio Itajaí-Açú. Em 1897, o primeiro projeto foi entregue pela firma alemã "Siemens \& Halske". O empreendimento deveria custar um total de 125.175 marcos alemães, algo em torno de 100:000\$000 (cem mil contos de réis) ao câmbio da época ${ }^{11}$. No mesmo ano, o jornal Blumenauer Zeitung já havia publicado a Resolução $\mathrm{n}^{\circ} 26$ da Câmara Municipal de Blumenau, autorizando a abertura de concorrência para a contratação de iluminação pública, que deveria ir do centro da cidade até o Salto, além de transmissão

\footnotetext{
${ }^{10}$ MORETTI, op. cit, p. 124.

${ }^{11}$ KILIAN, Frederico. Subsídios à crônica de Blumenau. Blumenau em Cadernos, tomo XX, n. 3, p.67, mar. 1979. (Notícia compilada do jornal Blumenauer Zeitung, de 1897, para a revista Blumenau em Cadernos).
} 
de energia elétrica dentro do Município de Blumenau, por um período de cinquenta anos ${ }^{12}$.

Um dos protagonistas da história da energia elétrica do vale foi o deputado estadual Peter Christian Feddersen. De acordo com muitos autores, Feddersen foi um romântico, com ideias de modernização e um dos primeiros a procurar recursos para a concretização de seu sonho de transformar as águas do Itajaí-Açú em energia elétrica. Diz-se, inclusive, que a Usina Hidrelétrica Salto Weissbach nasceu de suas ideias. De acordo com Godofredo Entres ${ }^{13}$ (1929, [s/p]), que não esconde sua admiração e visão romanceada da vida de Feddersen, o mesmo teria adquirido um terreno nas imediações da cachoeira do Salto, em 1885, e desde então, analisava a possibilidade de implantar uma usina na região.

Apesar disso, naqueles primeiros anos o sonho de Feddersen permaneceu apenas no papel. Em 1904, juntamente com os estudos realizados para a construção de uma via férrea que ligava Blumenau a Curitibanos, procedeu-se um novo estudo técnico para o aproveitamento do Salto. Apesar das atenções voltadas para o rio Itajaí-Açú, mais precisamente o Salto Weissbach, foi outro rio que recebeu a implantação da primeira usina do vale: o rio Gaspar Alto.

A construção da usina foi uma iniciativa do comerciante importador e exportador Frederico Guilherme Busch Sênior. O ano que marca o início do fornecimento de energia elétrica para a cidade de Blumenau é duvidoso, visto que cada autor sinaliza para um ano específico, no entanto, tem-se certeza de que tal fato ocorreu na primeira década do século XX. E não foi apenas a usina hidrelétrica que foi construída naquele momento, outras ações como a construção da estrada de ferro (iniciada em 1907) e bancos deram um novo impulso industrial para a região. E graças à energia produzida pela usina de Gaspar Alto, Blumenau passou a ser a primeira cidade catarinense a contar com iluminação pública ${ }^{14}$.

Apesar das dúvidas quanto ao início do fornecimento, o contrato de concessão para o estabelecimento de luz e energia entre Frederico Busch e o município de Blumenau data do dia 31 de outubro de 1910. De acordo com o contrato, Busch deveria estabelecer força e energia elétrica para a cidade de Blumenau e para a estrada geral até a casa de Frederico Specht e até o porto de Itoupava Seca. O contrato em questão teria um prazo de 25 anos e

\footnotetext{
12 Ibidem, p. 66.

${ }^{13}$ ENTRES, Godofredo. Usina Salto. In: Edição Comemorativa do Centenário da Colonização Alemã em Santa Catarina, 1929. [s/p].

${ }^{14}$ MORETTI, op. cit, p. 74.
} 
traz em suas cláusulas questões referentes à iluminação pública, valor do quilowatt-hora bem como especificações sobre o tipo de iluminação que deveria ser instalada em locais públicos ${ }^{15}$.

Infelizmente, a pequena usina construída não foi suficiente para suprir toda a demanda de energia elétrica da cidade que se encontrava em pleno desenvolvimento. Essa defasagem de fornecimento acabava acarretando em constantes perdas na produção industrial. Diante deste grande problema, a ideia da construção de uma usina em Salto Weissbach volta a ser pauta de discussão.

Desta forma, em 1909 foi fundada a empresa de Eletricidade Salto, que possuía quatro sócios, todos ligados ao comércio e a rede política de Blumenau. Dentre eles encontra-se o já mencionado Peter Feddersen, além de Gustav Salinger, Paulo Zimmermann e Carlos Jensen, todos proprietários de terras da região de Salto Weissbach. O grupo em questão teria inclusive ido à Alemanha atrás de financiamento para a realização da obra ${ }^{16}$. Mas foi necessário recorrer à empresa paulista Bromberg, Hacker \& Cia para que o projeto se concretizasse. A realização da obra custou mais caro do que a empresa "Siemens \& Halske" havia orçado, ao todo foi necessário um empréstimo de 1.831.113,2 marcos alemão, algo em torno de 219:244\$600 contos de réis ${ }^{17}$.

De acordo com o contrato firmado entre a municipalidade e os sócios da empresa, foi realizado no dia 18 de abril de 1912 o "[...] estabelecimento de um serviço de força e luz electricas no Municipio de Blumenau, em todos os territorios de seus limites actuaes fóra a zona dada em privilegio a F. G. Busch" "18. Observando os dois contratos (de Busch e do Salto), percebe-se que este último é mais completo. Possuía uma validade de trinta anos, além de pela primeira vez mencionar a questão industrial, alegando a obrigação de promover um aumento na produção na medida em que se manifestar as necessidades industriais. Além disso, o concessionário teria obrigação de iniciar a construção da primeira usina em no máximo um ano após a assinatura do contrato, bem como deve colocar

${ }^{15}$ Contrato entre o município de Blumenau e F. G. Busch, 31 de outubro de 1910, p. 1-3.

${ }^{16}$ BASTOS, Maria do Carmo dos Santos. Luzes e sombras: a História da Empresa Força e Luz Santa Catarina S.A. Florianópolis, SC, 1998. 113f. Dissertação (Mestrado) Universidade Federal de Santa Catarina, Centro de Filosofia e Ciências Humanas, Florianópolis, 1998, p. 33.

${ }^{17}$ MELRO, Luis de Freitas. A energia elétrica no rico Vale do Itajaí. In: Condensado de Empresa Força e Luz de Santa Catarina S.A, [s/p].

${ }_{18}$ Contrato entre o município de Blumenau e a Empresa Eletricidade do Salto, 18 de abril de 1912, p. 7. 
em funcionamento ao menos duas turbinas (de 2.000 cavalos de força cada uma) em no máximo dois anos. Caso essas exigências não fossem atendidas, o contrato de concessão do privilégio seria caducado ${ }^{19}$.

O que mais chama atenção no processo de instalação das usinas, que vai desde os primeiros estudos até os contratos firmados, é a ausência de uma análise da questão ambiental. Conforme mencionado anteriormente, a região em questão sofre com problemas de enchentes desde sua fundação e, ainda assim, após sessenta anos de experiência, os problemas ambientais são ignorados. Embora as usinas hidrelétricas não provoquem um consumo efetivo da água que pudesse levar ao esgotamento do recurso, elas apresentam impactos ambientais que devem ser levados em consideração antes de sua implantação.

A construção de grandes obras hidráulicas pode trazer impactos diretos e indiretos sobre o meio ambiente. Isso ocorre, especialmente, no caso das usinas, visto que é necessária a construção de grandes reservatórios para regularizar a vazão dos rios e fazer funcionar as usinas ${ }^{20}$. Dentre os impactos físicos, os mais comuns são "[...] a diminuição da correnteza do rio alterando a dinâmica do ambiente aquático, com isso o fluxo de sedimentos é alterado favorecendo a deposição deste no ambiente lótico" 21 . Além disso, também há uma alteração na temperatura do rio, levando a divisão do lago da represa em dois ambientes, um com temperatura mais baixa e outro com a temperatura mais alta ${ }^{22}$.

Apesar dos possíveis impactos, o projeto da usina do Salto foi feito para enfrentar as constantes enchentes da região. Para isso, a casa de máquinas deveria possuir $639 \mathrm{~m}^{2}$, com o pé direito de 21 metros, o porão foi projetado para ser inundado, "[...] servindo de sustentação para que a construção não fosse arrastada pela força da correnteza das águas. Ao mesmo tempo existiam comportas de ferro para serem fechadas, impedindo que as águas invadissem a casa de máquinas"23.

E foi assim que em 1913, teve início a construção daquela que seria, naquele momento, a maior Usina Hidrelétrica do Estado. De acordo com

\footnotetext{
${ }^{19}$ Ibidem, p. 8.

${ }^{20}$ VARGAS, op. cit, p. 113.

${ }^{21}$ SOUSA, Wanderley Lemgruber de. Impacto Ambiental de Hidrelétricas: uma análise comparativa de duas abordagens. Rio de Janeiro, 2000. Dissertação (Mestrado) Universidade Federal do Rio de Janeiro, Programa de Pós-Graduação em Engenharia Ciências em Planejamento Energético, Rio de Janeiro, 2000, p. 10.

22 Ibidem.

${ }^{23}$ BASTOS, op. cit, p. 47.
} 
$\operatorname{Bastos}^{24}$, até aquele momento Santa Catarina possuía três usinas, a Usina Maruim (atual São Pedro de Alcântara), de 1907, com capacidade de 600 kw, a Usina Piraí (Joinville), com $400 \mathrm{kw}$ e a Usina São Lourenço (Canoinhas), com $420 \mathrm{kw}$. A Usina Salto apresentaria uma capacidade de $6.300 \mathrm{kw}$.

Segundo Fritz Mailer, trabalhador aposentado da Força e Luz, nome dado posteriormente a empresa Eletricidade Salto:

[...] quem conhece a obra civil da Usina, se pergunta como os antigos trabalhadores efetuaram esta obra, com os precários apetrechos e máquinas que existiam na época. As grandes peças dos geradores e turbinas das primeiras máquinas, fundidas em aço, o transporte, enfim, é de se admirar e refletir, pois hoje é tudo mais fácil com a técnica avançada ${ }^{25}$.

A grandiosidade do empreendimento também foi destaque no jornal Blumenauer Zeitung do dia 25 de abril de 1914:

A grande quantidade de material que está armazenado nos galpões dão uma ideia da fantástica obra planejada, mas ao mesmo tempo também despertam a surpresa sobre o progresso do tempo moderno e o respeito pelos construtores e seus empreendedores. Nós desejamos primeiro a este empreendimento tão necessário para Blumenau, inicialmente um bom tempo e um nível de água favorável para a finalização dos trabalhos de base $^{26}$.

Conforme previsto em contrato, as primeiras foram ativadas no fim do ano de $1914^{27}$. No ano seguinte, novas turbinas passaram a funcionar. Desde sua inauguração, é perceptível o avanço industrial conquistado. É importante observar que a fase de implantação da primeira usina hidrelétrica do Vale do Itajaí coincide com um momento de turbulência política e econômica na Europa, que acaba por atingir diretamente o restante do

\footnotetext{
${ }^{24}$ Ibidem, p. 12.

${ }^{25}$ MAILER apud BASTOS,. op. cit, p. 46.

${ }^{26}$ Blumenauer Zeitung, 25 abr. 1914, n. 14, ano 33, [s/p]

${ }^{27}$ Blumenauer Zeitung, 23 dez. 1914, n. 80, ano 33, [s/p]
} 
mundo. Com o início da Primeira Guerra Mundial, as importações foram dificultadas, o que por um lado foi bom para a indústria nacional, já que não era mais possível comprar produtos europeus. Mas por outro lado, a dificuldade de importação deveria prejudicar a indústria local, visto que não era possível importar matéria-prima e máquinas para abastecer as produções. Além disso, os problemas econômicos gerados na Alemanha acabaram por impulsionar a vinda de novos imigrantes, sendo grande parte deles mão-de-obra qualificada, que acabaram se dedicando ao trabalho nas indústrias. $\mathrm{O}$ avanço das indústrias do vale nesse momento de turbulência demonstra como a Usina Salto Weissbach teve participação decisiva no desenvolvimento da região.

Além disso, a implantação da energia elétrica trouxe transformações significativas na estrutura de trabalho das indústrias. Segundo Hémery ${ }^{28}$, a eletricidade aumentou a exploração da mão-de-obra, em virtude do alongamento da jornada de trabalho. Sendo que seis anos após o início do fornecimento, foi criada a escala de trabalho noturno.

Logicamente, não se pode afirmar que o crescimento das indústrias se deu única e exclusivamente em função da construção da Usina Salto, no entanto, a participação dela é indiscutível. A indústria Hering, uma das maiores da região, é um exemplo disso. Em 1912, a empresa possuía um capital de 573.780,00 cruzeiros $^{29}$, passa a contar com 875.000,00 em 1915 e no ano seguinte atinge a marca de 1.025.000,00, chegando a apresentar um aumento de $21 \%$ entre os anos de 1919 e $1922^{30}$. O acréscimo de material para o trabalho também é relevante, em 1880 a Hering adquiria seu primeiro tear, em 1915 eles já somavam noventa unidades e em 1929 chega à soma de $170^{31}$. O mesmo se percebe na produção final de camisetas (carro-chefe da empresa), enquanto em 1915 se produziu 38.028 dúzias, em 1919 a produção era de 57.028 dúzias e em 1948 essa produção chegou a 234.905 dúzias $^{32}$.

Apesar da necessidade incontestável do empreendimento, a Usina Salto Weissbach foi vendida para um grupo financeiro de São Paulo, em 1920. Assim, a empresa Eletricidade Salto passa a se chamar Empresa Força e Luz Santa Catarina, "[...] com um capital de 3.000 contos em ações e 2.000 contos em debêntures" ${ }^{33}$. A fase paulista da Usina Salto não durou

\footnotetext{
${ }^{28}$ HÉMERY apud BASTOS, op. cit, p. 49.

${ }^{29}$ HERING, op. cit, p. 105.

${ }^{30}$ Ibidem, p. 211.

${ }^{31}$ Ibidem, p. 209.

${ }^{32}$ Ibidem, p. 215

${ }^{33}$ ENTRES, op. cit, [s/p]
} 
muito tempo. O aumento significativo da tarifa de energia elétrica e a recusa em aumentar os investimentos geraram descontentamentos entre os empresários catarinenses, que naquele momento já estavam se firmando no mercado nacional, e se sentiam afrontados pela postura da empresa. Visto que o fornecimento de energia elétrica era vital para as indústrias de Blumenau $^{34}$.

Sendo assim, quatro anos após a venda para a empresa paulista, um grupo catarinense, do qual se destacam dois dos principais industriais do Vale do Itajaí resolveram comprar a Empresa Força e Luz Santa Catarina. Foram eles Curt Hering e Otto Renaux, herdeiros diretos de Hermann Hering e Carlos Renaux, respectivamente. Com a transação, a sede da empresa foi transferida para Blumenau ${ }^{35}$.

O posicionamento dos principais proprietários de indústrias têxteis do Vale do Itajaí demonstra claramente a importância que a fonte energética gerada pelas águas do Rio Itajaí-Açú teve sobre a industrialização da região. A partir de meados da década de 1920, a Empresa Força e Luz não era mais apenas a fornecedora de energia elétrica para as indústrias do vale, ela é mais do que isso, ela é parte da industrialização. Nomes fortes na política e na economia catarinense, como Carl Hoepcke, Victor e Adolfo Konder, Carlos Renaux, família Hering, entre outros, aparecem intimamente ligados (muitos deles presidentes e acionistas) a empresa Força e Luz, assim como em outras empresas responsáveis pelo fornecimento de energia elétrica em Santa Catarina. Essa aproximação denota a importância vital que essas usinas tiveram para o fortalecimento da economia catarinense, sabidamente dependente em grande parte das indústrias têxteis de Joinville e do Vale do Itajaí.

Com o início da década de 20, linhas de transmissão começaram a ser instaladas por todo o vale. Em 1921, através de uma concessão outorgada a João Bauer, o município de Brusque começou a receber os fios da Força e Luz. No ano seguinte, foi a vez de instalar as transmissões em Indaial, naquele momento ainda distrito de Blumenau, dando-se o primeiro passo a linha de penetração a hinterland blumenauense. Em 1929, foi instalada a terceira unidade da Usina Salto, uma vez que as duas primeiras apresentavam sua capacidade quase esgotada. Dez anos depois foi instalada a quarta unidade, elevando para $9.000 \mathrm{cv}$ a capacidade do $\mathrm{Salto}^{36}$.

34 SINGER, Paul. Desenvolvimento Econômico e Evolução Urbana. Blumenau em Cadernos, Blumenau, tomo XXVII, n. 6, p. 192, jun. 1986.

${ }^{35}$ HERING, op. cit, p. 188.

${ }^{36}$ MELRO, op. cit, [s/p]. 
Além da questão elétrica, a Usina Salto teve um papel importante no período de enchentes. Apesar de ter gerado impactos sobre o meio ambiente, a usina acabou atuando no controle das cheias. Isto porque seus funcionários tinham como tarefa diária fazer a medição constante do nível dos rios, e assim era possível informar a população sobre a iminência das cheias. Essa previsão era de extrema importância para as localidades atingidas pelas enchentes, uma vez que sabendo com certa antecedência, era possível prevenir danos maiores ${ }^{37}$.

Em 1937, a Empresa Força e Luz faz um novo contrato de concessão, desta vez de exclusividade para produzir, transmitir, distribuir e vender energia para iluminação pública e particular. Apesar da exclusividade, era permitido que particulares produzissem energia elétrica, no entanto era proibido distribuir tal energia, sendo apenas para consumo próprio. Com um contrato de vigência de trinta anos, em momento algum, novamente, é levado em consideração as implicações ambientais do projeto $^{38}$.

Apesar do grande fornecimento de energia elétrica, com a aproximação do fim da primeira metade do século XX, o crescimento acelerado das indústrias gerou uma defasagem na produção de eletricidade. Sendo assim, nas décadas subsequentes, iniciaram-se as construções de duas novas usinas, a Usina de Cedros e, um tempo depois, a Usina Palmeiras. Naquele momento (década de 1940), a empresa Força e Luz atendia a 1.404 consumidores industriais e comerciantes, que absorviam $57 \%$ da produção de energia. Os $43 \%$ restantes eram consumidos pelos 8.036 consumidores residenciais. A construção da segunda usina proporcionou um grande aumento na economia da Força e Luz, uma vez que eles possuíam a concessão de fornecimento para todo o Vale do Itajaí, mas Salto Weissbach não era mais suficiente para suprir a demanda. Com a concessão de uma área de $10.125 \mathrm{~km}^{2}$, a Força e Luz foi pioneira na eletrificação da área rural do vale ${ }^{39}$.

A Usina Cedros (construída em 1954), com uma barragem de capacitação pequena, insuficiente para o seu funcionamento, dependia das condições climáticas, o que acabou gerando sérios problemas nos períodos de estiagem. No início da década de 1950 foi implantado o sistema de revezamento, as indústrias estavam proibidas de funcionar entre 18 e 22

\footnotetext{
${ }^{37}$ BASTOS, op. cit, p. 50.

${ }^{38}$ Contrato entre o município de Blumenau e a Empresa Força e Luz Santa Catarina, de 20 de novembro de 1937.

${ }^{39}$ BASTOS, op. cit, p. 71.
} 
horas, enquanto que as residências deveriam racionar o consumo durante o dia $^{40}$. Em função disto, em 1963 foi fundada uma terceira usina, localizada no rio Palmeiras. A usina começou a funcionar com duas unidades geradoras, aumentando a produção bruta da Força e Luz em 27\%, levando a desativação da usina termelétrica que havia sido implantada alguns anos antes junto a Usina Salto.

No ano seguinte, outras duas unidades foram inauguradas, fazendo com que a produção aumentasse em $40 \%$. Sendo que apenas a cidade de Blumenau respondia por $48 \%$ do consumo da produção da empresa ${ }^{41}$. Um ano após a criação da terceira usina, a Empresa Força e Luz foi incorporada à Centrais Elétricas de Santa Catarina S. A. (CELESC). Mais recentemente, foi construída a Usina Hidrelétrica Salto Pilão, que entrou em funcionamento em 15 de dezembro de 2009. De acordo com informações obtidas em seu site, a usina possui uma potência instalada de 191,89 MW, sendo o maior aproveitamento elétrico do Rio Itajaí-Açú. Apesar das novas construções, a Usina Salto Weissbach permanece em pleno funcionamento, com seu maquinário original.

Observando a documentação e a história da implantação das usinas hidrelétricas no Vale do Itajaí, chegam-se às seguintes conclusões: a primeira diz respeito ao papel do rio Itajaí na história da região, perceptível desde o início da colonização. A análise da industrialização só reforçou a importância que o rio tem para todo o vale. Foi em virtude do desenvolvimento industrial que a população pode descobrir uma nova forma de utilização dos recursos do rio, mostrando claramente sua importância nos ciclos econômicos e demonstrando as possibilidades advindas a partir da domesticação do rio. A aliança entre as indústrias e a empresa Força e Luz denota a dependência que esses grupos possuíam da Bacia Hidrográfica do Itajaí. No entanto, a utilização do rio proporcionou à indústria têxtil do vale do Itajaí uma independência, ao menos energética, em relação a outras regiões do país, auxiliando significativamente o seu crescimento econômico.

A segunda conclusão diz respeito à falta de atenção dispensada aos problemas ambientais durante longas décadas. Considerando-se que as enchentes eram e são o principal problema ambiental da região, é inadmissível que, ao longo do período em que se discutiu os projetos de construção de usinas, não se tenha pensado nas implicações ambientais dessa obra. Isso espelha as atitudes que o poder público e privado vem tendo sobre a questão ambiental ao longo de todos esses anos. O rio, como

\footnotetext{
${ }^{40}$ Ibidem, p. $76-77$.

${ }^{41}$ Ibidem, p. 82.
} 
qualquer outro elemento do mundo natural, apresentava-se única e exclusivamente como provedor das necessidades humanas, através do fornecimento de seus recursos. É em virtude desta visão, em todos os âmbitos, não apenas no que tange às usinas, que os desastres ambientais se tornaram um evento ainda mais frequente desde o início do século XX. 